\title{
Review on Roles and Challenges of Agricultural Extension System on Growth of Agricultural Production in Ethiopia
}

\author{
Waktole Bayisa Debelo \\ Jimma Agricultural School, Jimma University, Jimma, Ethiopia
}

Email address:

waktolebayisa@yahoo.com

\section{To cite this article:}

Waktole Bayisa Debelo. Review on Roles and Challenges of Agricultural Extension System on Growth of Agricultural Production in Ethiopia. Journal of Plant Sciences. Vol. 8, No. 6, 2020, pp. 189-200. doi: 10.11648/j.jps.20200806.11

Received: October 29, 2019; Accepted: December 11, 2019; Published: November 16, 2020

\begin{abstract}
Agricultural extension work in Ethiopia began in 1931 with the establishment of the Ambo Agricultural School which is one of the oldest institutions and the first agricultural high school offering general education with major emphasis on agriculture. In the recent development of the Ethiopian Agricultural Extension System, the participatory approach is complemented by a scaling"-up" of technologies or the establishing of best practice for technology transfer at larger scales. Agricultural extension staffs are involved in multiple activities of agriculture and rural development. In Ethiopia, for example, the goal of extension goes beyond implementing the national agricultural development goals of achieving food security, improving rural livelihoods, and Natural Resource Management (NRM). In many countries of the world, agricultural extension services had been transformed from training and dissemination of specific innovations to farmers' group formation and partnership-building with various service providers such as credit institutions. In Ethiopia, despite the massive amount of resources being put into the system by the state, the agricultural extension system faces a number of serious challenges. Improving access to agricultural inputs and technologies that assist farmers in boosting production are among opportunities of Ethiopian agricultural extension system. Agricultural extension service could be the government agency or ministry responsible for promoting the adoption and utilization of new scientific farming practices through educational procedures.
\end{abstract}

Keywords: Extension, Challenge, Role, Agriculture, Ethiopia

\section{Introduction}

Agricultural extension work in Ethiopia began in 1931 with the establishment of the Ambo Agricultural School which is one of the oldest institutions and the first agricultural high school offering general education with major emphasis on agriculture. In Ethiopia, agricultural extension is playing a crucial role in agricultural development and rural transformation. "Extension is understood as a policy instrument and legitimate tool for a government to bring about desired changes in political, socio-economic, cultural and environmental aspects [1]. Ethiopian agricultural extension approach has been changing over time [2].

In the recent development of the Ethiopian Agricultural Extension System, the participatory approach is complemented by a scaling "-up" of technologies or the establishing of best practice for technology transfer at larger scales. In spite of the reforms, implementation of agricultural extension in Ethiopia still features the classical model of technology transfer adopted in the past. Farmers are compelled to adopt new practices recommended as "onesize-fits-all" often with little consideration of socio-economic and biophysical variations across the country which is contradictory to the "best-fits" approach to agricultural advisory services (AAS) [3]. A persistent problem that faced the Ethiopian agricultural extension is a failure to distinguish between behavioral change through "coercion", and "voluntary" action [4].

There are a few assumptions as to why agricultural extension in Ethiopia is simultaneously employing contradictory approaches. Firstly, agricultural extension services are almost entirely provided and financed by the state [4]. Secondly, agricultural extension is used as an instrument for achieving the poverty reduction, food security and sustainable land-management goals of the country [5]. Thirdly, agricultural extension is a means by 
which the government can reach out to the majority of the population [6, 7]. Argues that rather than merely enhancing technology adoption and increased agricultural production, the government also seeks to maintain its rural support base.

Despite Ethiopia's huge investment in agriculture, significant change in the provision of advisory services has not been achieved [8]. The available services and the quality of service providers are no more efficient than before. As a result, rural poverty and food shortage still remain a challenge to the country $[9,10]$.

Furthermore, high input and low output prices, land degradation, climate change, and declining production are other barriers to agricultural development. Farmers access agricultural inputs in cash. Access to credit services from micro finance institutions demands group collateral of about five to ten farmers. It is challenging for farmers to find peers with common interests and commitment. Practically, this means they have limited access to credit, a lack which impedes technology adoption by resource-poor farmers. Throughout Ethiopia, farmers' cooperative unions have been established starting from the time of the Derg military regime [11] with the aim of increasing production and income by providing them with finance, agricultural inputs, information, and output markets [12].

Agricultural extension staffs are involved in multiple activities of agriculture and rural development. In particular, Development Agents (DAs) provide general advisory services in crop, livestock, and natural resource management at the level of the sub-kebele, the administrative unit directly below the kebele [1]. However, DAs' annual performance evaluation is worked out based on their respective disciplinary backgrounds (crop, livestock, or natural resource management). Therefore, their involvement and contribution as generalist DAs in their respective kebele is not eventually accredited [13]. DAs also lack proper mentoring support from Subject Matter Specialists (SMS) based in the woreda Office of Agricultural Development [14]. On top of the aforementioned issues, agricultural staff in general is the most poorly paid members compared to other sector offices in the woreda. The DAs also often lack job amenities and incentives such as daily allowance or top-up, shelter, transportation facility, insurance, or field kits.

\subsection{Statement of the Problem}

There were many studies conducted to identify role and challenges of extension service in Ethiopia in different region but there is limitation of reviewing of current state of understanding on roles, and challenges of agricultural extension service and not deeply show available opportunities that stakeholder and farmers have in their environment. So review of roles, challenges and opportunities is crucial for future policy formulation in the country. This study has identified some of the roles, challenges and opportunities of agricultural extension service.

\subsection{Objectives}

\subsubsection{General Objective}

To review on Roles and Challenges of Agricultural extension system on growth of Agricultural production in Ethiopian

\subsubsection{Specific Objective}

1) To review Roles of Agricultural extension system in Ethiopia

2) To review on Challenges of Ethiopian Agricultural extension system

3) To review historical perspective of agricultural extension and its progress in Ethiopia

\section{Methodology}

Data used in this paper were collected by reviewing of journals and articles, theoretical and empirical; evidences that related to agricultural extension systems' roles, opportunities and challenges to reach a conclusion.

\section{Review of Literatures on Roles and Challenges of Agricultural Extension System on Growth of Agricultural Production in Ethiopia}

\subsection{Definition and Operationalization of Concepts and Terminologies}

Agriculture is the cultivation of plants and husbandry of animals, that is, the management of living things and ecosystems to produce goods and services for the people.

Agricultural extension is the application of scientific research and new knowledge to agricultural practices through farmer education.

Opportunity is a situation in which it is possible for you to do something that you want to do.

Challenge is something new and difficult which requires great effort and determination

Extension is defined as a mechanism for facilitating awareness and knowledge of the underlying social and physical processes and Extension has traditionally been defined as the delivery of information and technologies to farmers. The term "extension" and the activity it covers is rather complex [15]. Countries and scholars define extension differently and contextualize it in terms of their own situations. The uses of the term "extension" also vary between developed and developing countries. The term "advisory services" is an alternative to "extension" in the UK, Germany and the Scandinavian countries [16] differences in the terminology are not the only sources of confusion with respect to the concept extension' but the politics and other traditions have made a considerable contribution. Therefore, extension is expected to take on different roles depending on the policy and purposes within 
which it functions in different countries and among different scholars.

The Malawian Department of Agricultural Extension Services reported that in 2012 there were a total of 2,415 field and office staff members. There were more male extension workers (80 percent) than female extension workers. The farmers per government extension officer ratio in Malawi was estimated to be between 1,800 a number much higher than those of other countries in the region, such as Ethiopia, the Democratic Republic of Congo and Kenya.

Table 1. The ratio of extension agent to farmers in developing country.

\begin{tabular}{lll}
\hline Country & $\begin{array}{l}\text { Number of extension } \\
\text { agents DA }\end{array}$ & $\begin{array}{l}\text { Ratio of agents to farm } \\
\text { families }\end{array}$ \\
\hline Ethiopia & 63,000 & $1: 476$ \\
Bangladesh & 14,092 extension agent & $1: 900-2,000$ \\
$\begin{array}{l}\text { Guinea } \\
\text { Liberia }\end{array}$ & 800 extension agents & $1: 10,000$ \\
Malawi & 2,415 extension agent & $1: 1,000-1: 5,000$ \\
Mozambique & 1,304 extension agents & $1: 111-1: 787$ \\
Nigeria & 7,000 extension agents & $1: 5,000-1: 10,000$ \\
Senegal & 500 extension agent & $1: 753$ \\
Kenya & - & \\
\hline
\end{tabular}

Source: (Cunguara et al., 2018) (Lefort, 2012).

\subsection{The Historical Perspective of Agricultural Extension and Its Progress in Ethiopia}

The land tilled by the Ethiopian small-scale farmer accounts for $95 \%$ of the total area under agricultural use, and these farmers are responsible for more than $90 \%$ of the total agricultural output; rural development policies and programmes are usually developed to suit the condition of progressive farmers. Knowledge and awareness about the relative importance of each package component to overall yield give farmers room for flexibility in stepwise adoption of the technology, according to their conditions and resources; Development agents, extension professionals, subject matter specialists, farmers' representatives, politicians and researchers tend to contact only them. Policy makers and donor agencies have so far been emphasized the use of modern farm technologies as a sole source of agricultural growth in Ethiopia; Agriculture is the mainstay of Ethiopian economy involving major source of employment and gross national product. By African, standard rural development programme has long history in Ethiopia. It has also enjoyed a considerable attention by the government. However, the expected level was not achieved.

Theories of agricultural development policies include the (frontier; the urban industrial impact; the diffusion; the high pay-off; the induced innovation; and the conservation) models.

i) The frontier model or the resource exploitation model involves an approach to agricultural growth through the expansion of the area cultivated or grazed;

ii) The high pay-off model, which is also known as "the transformation approach" or "the quick-fix approach", is based upon investment designed to expand the diffusion and adoption of the high-yielding varieties. In Ethiopia, an attempt was made to partially introduce this model (along with the diffusion model) in the Comprehensive Package Project areas, where it had a strong impact, in particular in Chilalo district of Arsi region;

iii) The conservation model of agricultural development, "evolved from advances in crop and livestock husbandry associated with the English agricultural revolution and the notions of soil exhaustion suggested by the early German chemists and soil scientists.

In 1993, Ethiopian government adopted Agricultural Development-led Industrialization (ADLI)_as an overall development strategy. Government believed that agriculture was the leading economic sector and that the development of other sectors hinges upon achievements in agricultural sector. These beliefs have been the guiding framework for three successive development plans:

(i) Sustainable Development and Poverty Reduction Programme (SDPRP), which covered the years 2002/03-2004/05;

(ii) Plan for Accelerated and Sustained Development to End Poverty (PASDEP) for 2005/06-2009/10;

(iii) Growth and Transformation Plan (GTP) for 2010/112014/15;

Based on these successive development plans, the Ethiopia Government adopted policies and strategies to address agriculture and rural development. These are the Rural Development Policy and Strategy (RDPS) and the Food Security Strategy (FSS). The overall development strategy and RDPS focuses on smallholders. It envisages that productivity of smallholder agriculture will be improved through the distribution of improved seeds, fertilizers, tools, and pesticides; provision of improved extension services; construction of small-scale irrigation schemes; minimization of post-harvest losses; and development of livestock resources through improved feed and veterinary services, and increased use of improved breed and livestock products. Further, RDPS intends to address the proper use of land, expanding rural infrastructure (health, education, access to safe water, and rural roads), improving smallholders' access to the rural financial system, and developing and strengthening rural institutions.

In many countries of the world, agricultural extension services had been transformed from training and dissemination of specific innovations to farmers' group formation and partnership-building with various service providers such as credit institutions [19]. Decentralization of the organization and management of the extension is a common tendency in today's world. Decentralization implies the transfer of political power from central to local governments, and it is a means of improving the efficiency and accountability of the public sectors [20].

The development of Ethiopian economy heavily depends upon the speed of agricultural growth. The rate of agricultural growth in Ethiopia in turn depends on the speed the current subsistence oriented production system transformation into market orientated production system. Among the many institutional support services to 
catalyze/support the transformation process is agricultural extension service that can play a critical role, since it contributes to the development of the skill and knowledge of farmers to adopt new and improved technologies (seed varieties and animal breeds, implements, chemicals and practices), and approaches and processes with which the skill development and access to information are realized.

Extension system should encompass five goals: transferring knowledge from researchers to farmers; advising farmers in their decision making; educating farmers to be able to make similar decisions in the future; enabling farmers to clarify their own goals and possibilities; stimulating desirable agricultural development. To reform the extension system, three strategies have been implemented. Decentralizing the burden of extension expenditures such as direct charging of extension services, provision of coupons or vouchers; decentralizing the responsibility of the central government for extension; decentralizing the management of programs through farmers participatory; involvement in decision makes leading to farmers taking responsibility for extension programs.

Ethiopia has also embraced decentralization as a process for the transformation of its agricultural extension service to bring it closer to the farmers through farmers' group formation, thereby enhancing participation. Despite this, the system is highly oriented towards top-down approaches in technology transfer with quasi participation by farmers often compulsory based on unrealistic and poorly planned quota systems. The level of "decentralization" in agricultural extension is weak, since the woreda still relies on the regional plan. Basically, both the indicative plan as a target for steering the planning exercise by the woreda and the actual implementation plan after the amendments by BoAD are sent back to WOAD for implementation.

Many of the expected benefits of decentralization have been based on the increasing political commitment. Those officials who are politically strong and compliant with the system could have the chance to make decisions, but most are debilitated by lower levels of education, lack of confidence in their ability to move out of a given political orbit and follow the necessary program, Therefore, voluntary farmer participation in agricultural extension and rural development has not really happened as expected.

In Ethiopia, public agricultural extension services have been in action for about half a century. Studies show that Ethiopia has the largest agricultural extension system in SubSaharan Africa, and third largest in the world after China and India [21]. According to the Bill and Melinda Gates Foundation a total of 8,500 farmer training centers (FTCs) have been established and 63,000 field extension workers (known as development agents-DAs) have been trained. The current extension approach, therefore, follows FTC-based extension system. The FTCs are positioned to facilitate agricultural knowledge and information exchange among researchers, extension workers and farmers. Woreda level agricultural offices are responsible for managing the operation of FTCs with the support of zonal and regional agriculture bureaus and are the frontline administrative structure for implementing agricultural extension services in the country. The experts (called subject matter specialistsSMS) in each woreda provide technical support and training to DAs. Most of the FTCs have at least three development agents one for crops, livestock, and natural resource management.

\subsubsection{Regional Agricultural States}

Ethiopia is a federal country with nine regional states and two city administrations [22]. Regions play a key role in planning and implementing the agricultural extension and rural development. At regional levels, the head of the regional $\mathrm{BoAD}$ is also deputy head of the regional administration. The purpose of power sharing with the administration is to empower the agriculture sector as the backbone of the economy. In the counter-analysis, however, the power sharing of the administration with agricultural sector tends to create uniform political opinion between the agriculture sector and the administration.

The BoAD is structured in similar patterns to the MoANR, though, based on the decentralized governance system, regions can reform the structure to suit their own context up to kebele level. In Oromia and SNNPRS, the agricultural extension department of regional $\mathrm{BoAD}$ engages in suitable technology generation, identification and adoption, and also organizes the capacity building of zone and woreda actors through ToT.

This review shows that the reporting system is one of the prevailing limitations on the effectiveness of the AES. Reports are made through the agricultural development "Command Post". The Command Post is an integrated information development and reporting system developed by the MoANR to facilitate information flow [23]. However, the Command Post often imposes pressure and induces production of exaggerated and logically unreliable reports.

\subsubsection{Zone Agricultural Extension Department}

The Zone Office of Agricultural Development (ZOAD) serves as a transition between the regional BoAD and the WOAD. The ZOAD is intended to harmonize the bottom-up and top-down planning systems. In addition, it distributes the five-year Growth and Transformation Plan (GTP), the strategic plan of the country adopted by the Council of Ministers and the Parliament and distributed through the MoANR to the BoAD to be further disbursed to the woredas for implementation. While woredas are targeted to facilitate the implementation of such plans, zones play the role of linking regions and woredas concerning national and regional development policies, strategies, and programs. However, the role and power of zones in Ethiopia differ from region to region. The zones in Oromia region are generally weaker than in SNNPRS. In Oromia regional state, zones do not have councils or independent budgets.

\subsubsection{Woreda Agricultural Extension Department}

Since the 1990s, decentralization of governance in Ethiopia particularly empowers the woreda. The woreda is 
fiscally independent, with its own budget for staff, infrastructure, and the provision of AAS. The extension department of the WOAD provides training and backstopping services to the DAs through its SMS. In Oromia, the woreda agriculture controls the kebele activities through its supervisors, but the same job is also conducted by the Kebele Office Head in SNNPRS a role that was instigated in 2014 with the aim of strengthening the coordination of agricultural extension activities at kebele level.

The agricultural extension system operates under the leadership of the BoAD. The decision to install woredas as key administrative units was less motivated by questions of decentralization or ethnic identity than by the intention to extend governing authority down to local levels. Moreover, in practice, the woredas do not have adequate planning and implementation capacities. Such limitations might prolong reliance on regional top-down plans and curb community participation and local people's sense of belonging to the processes. Basically, the woreda administration is organized into $28-32$ sector offices. The WOAD is one of the sector offices that strive to address agricultural transformation with a focus on smallholder farmers. Similarly to the region and zone, the woreda administration shares the power with the WOAD head.

\subsubsection{Kebele Agricultural Extension}

Below the woreda, the kebele cabinet is the final decisionmaker in rural governance, agriculture and rural development. The "extension unit", is another decisionmaking body within the kebele agriculture. All state bodies including the kebele Command Post operate under the leadership of the kebele administrator. In Oromia, in addition to the supervisors from WOAD, DAs receive direction from the kebele administration. This is why $60 \%$ of the DA's performance is assessed by the kebele administrator and its cabinet members [23]. In Oromia, DA coordinators continue to play their coordination role in addition to providing the extension services in their own specialized fields of study, which still incur additional pressure on the DAs who serve as coordinators. Overall, DA's mandates are to provide training and backstopping services to development team leaders, provide occasional skill training to farmers, visit farmers' fields, facilitate their access to agricultural inputs, demonstrate technologies, and collect information about farmers' needs (in the form of input plans [4].

\subsubsection{Kebele Extension Unit}

The kebele extension unit is a group of people led by the kebele administrator who play a key role in making decisions on agricultural extension in the kebele. Each kebele is further divided into three sub-kebele. The kebele extension unit is expected to play the leading and coordination role in all forms of technical support to the Farmers' Training Centers (FTCs). Most rural kebeles have a FTC built by the state, but the degree of their operation and possession of farmland for technology demonstration vary from kebele to kebele. In Ethiopia through region up to kebele, the FTC is not yet effective in uniformly demonstrating technology to all farmers, because of different constraints, like:- very small demonstration plots, budget for technology demonstration and institution.

\subsubsection{Development Zone}

Every kebele is subdivided into three zones, with one DA assigned to each to provide "effective" extension services closer to the farmers. In principle, the three DAs are temporarily assigned by the kebele cabinet to one of the three zones on a rotational basis. In reality, however, the DAs are often permanently working in only one zone. The aim of the zones division is to facilitate networking among farmers to improve information flow and M\&E, in groups of about 240 to 300 farmers to each DA [4]. Every zone consists of about 6 to 10 development teams with 20 to 40 farmers each, on average. However, the number of development teams and farmers in each team varies from woreda to woreda. However, the zone is not represented by farmers' representatives to provide the networking services.

\subsubsection{Development Team}

A development team is a group of 20 to 40 neighboring farmers presumed to support one another in farming, training, and experience sharing. According to this review, development team has one leader and five members. The five members are model farmers who are serving in the development team. The number of members might be more or fewer based on the size of the village population and farmers' political inclinations. In line with [16], the decentralization process has often been paired with pluralism, involving various actors as a solution to the gaps in service provision prevailing in Ethiopia. For example, pluralistic extension services can help in addressing context-specific needs. There has not been an effective mechanism for the inter linkage of agricultural extension, research, and development actors in Ethiopia.

\subsubsection{Capacity of DAs to Provide Extension Services}

The skills of DAs and quality of training are vital to provide effective agricultural extension services. In Ethiopia, however, there is a mismatch between the relatively large number of trained extension experts (DAs) and their relatively low capacities to provide efficient and effective services. [2] Show that DAs and other extension staff appear to have limited skills. DAs are currently trained in Agricultural Technical and Vocational Education Training (ATVET) Colleges. This is done based on the recently adopted level-based training, which ranges from L1to L4, with an intervening Certificate of Competence examination to improve the quality of training. The training curriculum is narrowly specialized with specific focus on crops and/or practices such as horticulture, apiculture, or silviculture alone.

The ATVET capacities and structure differ from region to region. In Oromia region, the ATVET Colleges were commissioned by the BoAD. The responsibility was then transferred to the Agency, and eventually placed under the TVET Commission in 2011. In SNNPRS, the ATVET Colleges were devolved once from the MoARD to the BoAD, where they are still operating. 
Summary of above Agricultural Extension Systems' Structure framework

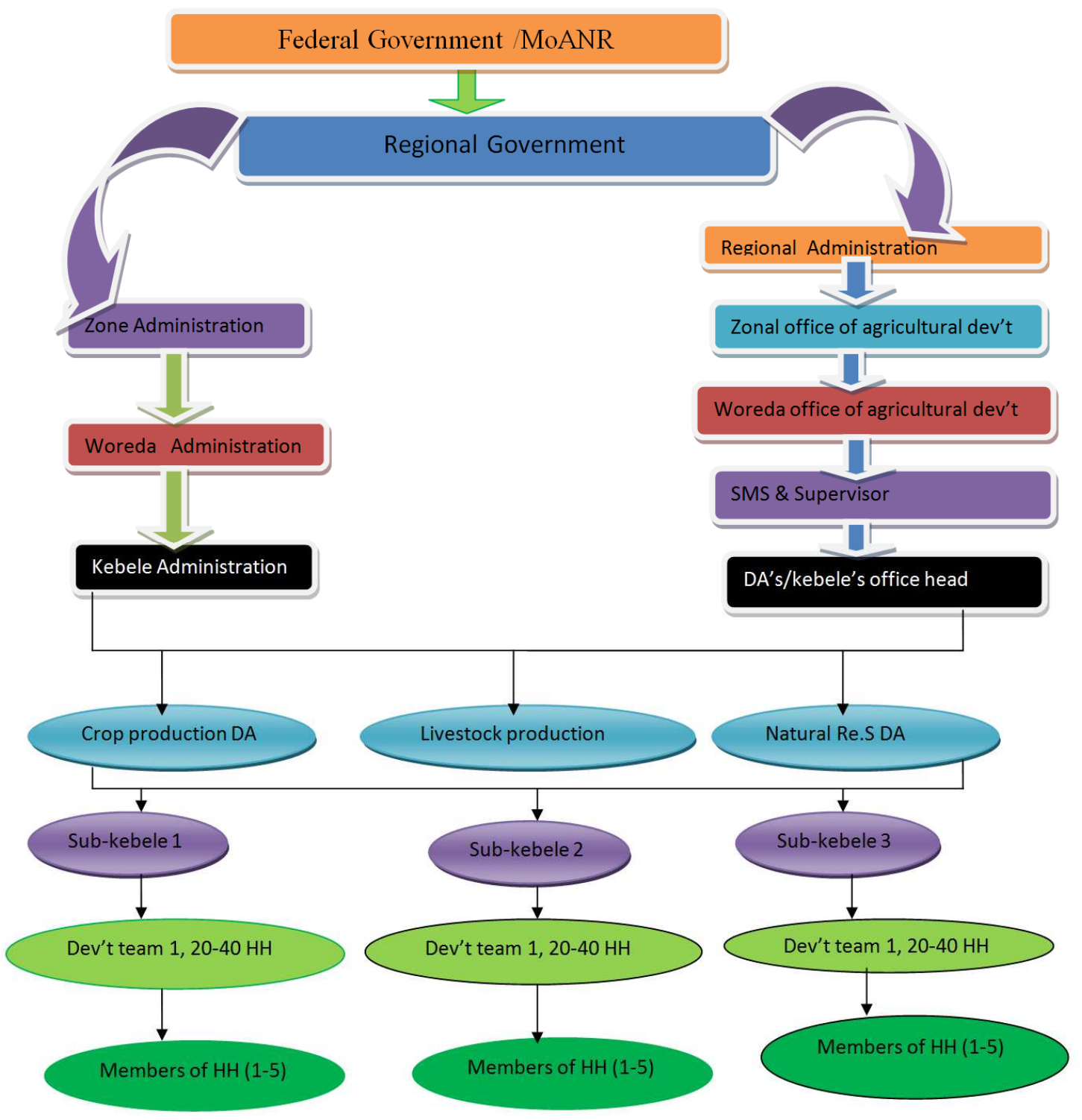

Figure 1. Source Adopted from Report [14].

The above figure 1 show that the framework summery from (page 4 to 17) of agricultural extension system of Ethiopia on growth of agricultural production and productivity and the chains or sequence of agricultural transformation and administrative structure from federal office to an individual at kebele level.

\subsection{Roles of Agricultural Extension System on Growth of Agricultural Production in Ethiopia}

A role may be defined as a set of norms, values and interaction patterns associated with a given category of individuals. Agriculture extension has a role to play in agriculture development. Agricultural extension service could be the government agency or ministry responsible for promoting the adoption and utilization of new scientific farming practices through educational procedures.

In Ethiopia, for example, the goal of extension goes beyond implementing the national agricultural development goals of achieving food security, improving rural livelihoods, and Natural Resource Management (NRM). Accordingly, the methods used in extension service provision vary from country to country. There are two main arguments regarding provision of AAS. The first underlines "public agricultural extension" as the main "development actor" in providing AAS to smallholder farmers with low income, since poor farmers may not be able to pay for the services themselves, the second argument highlights the promotion of transition to a pluralistic AAS. In pluralistic agricultural advisory services, a set of stakeholders and institutions or partners engage and support farmers in solving their development goals [3]. Pluralistic agricultural advisory services are likely to better meet the diversity of rural life and needs. Using more than one organization to deliver services to farmers is gaining popularity in countries such as China and India [21]. 
In places where private organizations are economically competent, government monopoly is not encouraged. In essence, "pluralistic agricultural advisory services is a service orientation and a move away from top-down models of technology transfer" [16].

Therefore, along with the public, involving the private sector and NGOs could accelerate improvement in agricultural advisory services especially in providing technical inputs, information, and training [21]. Thus, striking a balance between public, private, and NGO involvement in AAS could better address the emerging needs of advisory services in the growing economy. Experience has shown that extension services which accommodate farmers' varying interests, needs and capacities help to improve agricultural production and thereby to reduce rural poverty and food insecurity in poor countries like Ethiopia. Hence, The AAS, thereby, enables the smallholders to meet the Sustainable Development Goal (SDG-2) by increasing agricultural productivity with the aim of achieving food security, improving nutrition, and nurturing agricultural sustainability [17].

\subsubsection{Agriculture Commercialization}

According to these researchers, agricultural commercialization aims to bring about a shift from production solely for domestic consumption to production dominantly market-oriented. In line with the aforementioned defined commercialization of smallholder production as "a process involving the transformation from production for subsistence to production for the market, found out that most definitions refer to agricultural commercialization as "the degree of participation in the output markets with the focus very much on cash incomes".

The rate of agricultural growth in Ethiopia in turn depends on the speed with which the current subsistence oriented production system is transformed into a market orientated production system Among the many institutional support services that need to catalyse/support the transformation process, the agricultural extension service plays a critical role, since it contributes to change farmers skill, knowledge and attitudes in agricultural technology, farming activities and agricultural marketing.

Governmental and non-governmental institutions participates in developmental activities to enhance smallholder commercialization by delivering inputs like fertilizer, seeds, plant protection chemicals, and other related services. Consequently, access to such institutions improves smallholderse commercialization process. Research findings show result in line with this statement, concluded that farmers nearest to agricultural extension and research Institutes adopted improved technologies. As a result, access to Research Institutes and Agricultural Bureaus will enable farmers to get expertise advice and knowledge about the newly released varieties by taking part in participatory research like farmers research group, advisory council meetings and participatory variety selection.

\subsubsection{Food Security}

Food security is often defined in terms of food availability, food accessibility and food utilization as cited by [19]. Extensionists have received training which combines technical knowledge and communication skills. They can apply this knowledge to help in improving farming, farm yields and thereby reduce poverty. A general consensus exist that extension services, if properly designed and implemented, improves agricultural productivity.

A well-coordinated support system of agricultural extension and agricultural research was taken as a means of enhancing opportunities for improving the performance of the sector with a view to reducing poverty and food insecurity. Other associated goals enshrined in the strategy included commercialization of smallholder agriculture through product diversification and a gradual shift to highvalue crops for domestic consumption and export. Interventions that are compatible with the country's varied agro-ecological zones were designed by taking into account the country's comparative advantage in terms of reliable availability of labor, land and agro ecological diversity.

Properly designed and implemented extension service improves agricultural productivity and achieves food security. Not only but also livelihood diversifications and linking smallholders to market improve food security of rural poor.

\subsubsection{Conservation of Natural Resource}

Farmers and communities have little urged to conserve resources unless they are forced by legislation [23]. An extensionist does not use force but known strategies of persuasion to assist farmers and communities to conserve natural resources. The reason why communities have not given attention for natural resource is some people have different livelihood that if one damaged they have other livelihood and others lack interest, poor, lack of knowledge, skill. So agricultural extension is not only transfer technology. It improve farmers' skill, knowledge, attitude through training, providing information and communication concerning with agricultural practice and watershed management.

\subsubsection{Dissemination of Useful Information}

For many years it thought that farmers' conservatism was the reason for their failure to adopt new technology developed for them by agricultural scientists. Extensionists usually persuade farmers to adopt new practices mainly because they have access to research and its results [23]. They have received proper training that can be executed to benefit the farming communities. Extensionists should access different information needed by farmers in terms production, cultural practices, markets and marketing. What extension should disseminate to farmers may include: - technology transfer; - offering economical advice; developing agricultural markets and informational system; - developing small enterprises and discovering new alternatives for obtaining profits. 


\subsubsection{Promote Sustainable Agriculture}

Extension could play a central role in fostering sustainability through its educational programs but there has been a growing realization that traditional extension models have not been sufficiently effective in promoting adoption of sustainable agricultural practices. Since sustainable agriculture is a knowledge intensive system, it requires a new kind of knowledge, which differs from other forms on the basis of conventional agricultural practices. In fact, conventional extension system cannot accomplish sustainability in agriculture; because today's agricultural extension must consider environmental implications, social issues, and overall economic growth within the agriculture sector. Sustainability of agriculture is very use-full to cut vicious circle of poverty in developing country. This achieved through adoption and innovation of improved agricultural practice, livelihood diversification and development of different adaptation strategies for agriculture depend societies.

\subsection{Challenges of Agricultural Extension System on Growth of Agricultural Production in Ethiopia}

Most African agricultural extension system is facing different challenges. The Nigeria Agriculture Public Expenditure Review (NAGPER), a collaborative study carried out by a research team from the International Food Policy Research Institute (IFPRI) showed that public spending on agriculture in Nigeria is less than 2 percent of total federal expenditure during 2001 to 2005 . Also, there is very limited access to modern improved technologies and their general circumstance does not always merit tangible investments in capital, inputs and labor.

Also in Mali both quantity and quality are lacking in extension's human resources, especially with regards to subject matter specialists. Supervisors had low managerial capacity. In addition to technical skills, extension professionals need functional or "soft" skills to work effectively with clients such as group development, communication, facilitation, extension methods and informal adult education or entrepreneurship. In general, as in Guinea, Liberia, Ethiopia and Honduras, there is limited focus on functional skills. In Malawi, in contrast, there is more effort to train extension workers on functional skills.

Despite the potential role that FTCs and DAs can play in knowledge and information dissemination, a number of factors pose limits to the proper implementation and success of the program. In this regard, inadequate infrastructure and localized technical information, as well as budgetary shortfalls are some of the major constraints that inhibit effective agricultural knowledge management and delivery of agricultural extension services in Ethiopia [2]. Most FTCs have no access to electricity and do not have electronic equipment such as TVs and computers that they need to effectively discharge their work. In addition, only very few FTCs have advanced teaching equipment such as computers and access to the internet. Even when access and equipment are available to development agents, there is need to train and upgrade their skills. This upgrade is necessary because most of the development agents and extensions workers have limited ICT skills to optimally utilize them in their daily agricultural extension work with smallholder farmers.

Ethiopian Institute of Agricultural Research (EIAR) and regional agricultural research centers deliver agricultural research activities to farmers mostly through SMS, development agents and FTCs. EIAR also oversees the work of federal research centers and coordinates all agricultural research activities in the country. On the other hand, Regional Agricultural Research Centers (RARCs) are run by the respective regional governments within their regional bureaus of agriculture. Both EIAR and the RARCs have research-extension coordination departments, which tries to link research activities to agricultural extension. These linkages are currently weak and need to be improved in order to use them as a vehicle for generating, transmitting and updating agricultural knowledge and practices of smallholder farmers [2]. This is important in making agricultural research and extensions services play a key role in raising output and productivity of smallholder farmers and there by contribute to doubling of production and productivity of smallholder farmers by the end of the GTP period in 2015 .

Despite the role and power vested in the AED to develop the national strategy for an agricultural extension system, the MoANR has no such strategy. As a result, the actual implementation strategy of the country is vulnerable to spontaneous and frequent changes [1]. This is not only an impediment to the establishing of clear long-term goals for the agricultural extension of the country but also influences the interest and commitment of internal and external stakeholders regarding their involvement in the agricultural extension system. So far, there is no enabling policy environment or space that invites the private sector to provide AAS, so pluralism in advisory services is lacking. As a result, advisory services are mainly provided by Ethiopian state bodies, except for a few NGOs and development projects and programs, which are substantially contributing to capacity-building and the introduction of new skills and innovations in pocket areas [4].

As mentioned by [2]. Most FTCs have no access to electricity and do not have electronic equipment such as TVs and computers that they need to effectively discharge their work. Most of FTC in Ethiopia have not fulfilled minor equipment (materials) like desk, bench, backboard, shelf, etc which is initial and the least for farmer training center.

\subsubsection{Technical Challenges}

DAs' training focuses on technical skills. [2], DAs lack the required hard skills on issues important to the farmers such as agricultural marketing (value chain) and agricultural intensification and diversification and also lack soft skills such as process facilitation, communication, and organization of farmer-producer groups. According to our study, most DAs are rather specialized and lack the comprehensive and applied skills required to combine crop, livestock, and natural resource management. Eventually, most of them do not 
continue to commit to this work as they had in the beginning. Many DAs' work is not strategic or goal-oriented; rather, they target the short-term benefits interview code no. 62, [2015]. As a result, despite the large local staff and extension coverage in rural Ethiopia, the system has relatively little impact. The intention to cover wider areas of state interest such as provision of generic advisory services in crops, livestock, and natural resources by specialized DAs, and their involvement in non-extension affairs, could influence their capacity to address specific activities [1].

There is also poor coordination between the SMS. The main reasons for inadequate technical support are the shortage of resources; transportation and manpower. As a consequence, the SMS are relying on the checklist to collect progress of the extension activities through the DAs.

Degraded and abandoned lands are retargeted merely to achieve the seasonal quota plan. The watershed management plan also lacks integration of maintenance work with the new plan for physical soil and water conservation structures. As a result, the campaign ends up with an unpromising outcome. Additionally, mobilization that is associated with the punitive norms or approach employed to mobilize and engage the farmers in Watershed Management (WSM) triggers most farmers to associate the WSM intervention to the Derg military regime's natural resource management campaign, which farmers learned to be fearful of due to its entirely coercive approach.

Technically Lack of suitable adaptation of technology packages to local conditions shows that yields of major crops under farmers' management are still far lower than what can be obtained under research managed plots [4]. This is the result of research and extensions that were put in place used one size-fits for all types of extension methods and there is no extension that suits for all categories of adopters. Available empirical literature points to the fact that public sector agricultural extension system in Ethiopia has not been effective in terms bringing large scale adoption of improved technologies and practices by small scale farmers. A short list of the causes for the poor performance of the agricultural extension system includes: the distraction of extension workers by their involvement in input supply, collection of taxes and loan repayments; the limits of standardized packages, and the emphasis on input targets rather than affordability and profitability; failure to involve farmers in research problem identification, problem prioritization and extension program planning; extension agents' ignorance of farmers' traditional and experience-based knowledge system; lack of relevant research results; inadequate planning and coordination, and lack of interaction with research; and the formulation of extension programs and policies without due consideration to the farmers' opinion and traditional knowledge system [18].

In addition to technical problems mentioned above by different authors, the perception that university graduates and other farmers for agriculture is poor. People don't believe as agriculture create employment opportunity for jobless educated and uneducated people

\subsubsection{Policy-related Challenges}

Abate [1] described it as "rapidly changing policy signals" in which case the state frequently sends signals that induce swift changes. As a result, the system has been rapidly changing, from national-scale activities such as intensive national focus on water harvesting, to rain fed agriculture, etc. In addition, there are gaps in decentralization and the woredas' decision-making power. Despite the introduction of a decentralized system since the early 2000s the woreda implements regional plans. Concepts of decentralization should theoretically encourage public participation [21].

In a decentralized system, the ruling elites at the central level rather seek to expand and consolidate their support base by integrating with local elites. This happens in Ethiopia through the model farmers and kebele administration. Such a nominal decentralization system could deprive the WOAD of the power and authority to make independent decisions in agricultural extension.

The agricultural extension system in Ethiopia is strongly linked to politics. According to [6], it is hard to create the conditions for "a dynamic demand-driven system" when extension workers are also promoting a political agenda. The influence of politics in the agricultural extension system can be pointed out as one of the reasons for it slows effectiveness. DAs themselves could not independently call farmers' meetings for advisory services.

The focus of the agricultural extension system in Ethiopia is also on technology transfer. According to Abate [1], agricultural extension in Ethiopia has given little attention on problem-solving skill development and the organizational aspects required helping farmers help themselves. The system is highly structured in a top-down technology-transfer fashion. DAs may urge farmers to "take and use" new technologies, but rarely encourage them to develop and adapt technologies to their own situations.

Cognizant of the centrality of the agricultural sector, the EPRDF regime formulated the Agriculture-Led Development Industrialization (ADLI) Strategy in the mid-1990s when modernizing traditional smallholder agricultural production became the central focus. ADLI also formed the basis for the 'Plan for Accelerated and Sustained Development Programme' (PASDEP) implemented between 2005 and 2010 as a result of which Ethiopia hoped to realize most of the targets enshrined in the Millennium Development Goals (MDGs).

EPRDF's agricultural policy commenced with the introduction of the Agricultural Development-Led Industrialization (ADLI) Strategy in the mid-1990s. The main arguments made to justify this as an overarching economic policy were that improving the performance of smallholder agriculture could lead to increase in farmers' income, reduction of poverty, and enhancement of production of industrial raw materials including marketable surplus. The government strongly believes that ADLI is the fastest way to ensure economic development and recovery. However, critics doubt its efficacy by arguing that ADLI tends to disregard labor productivity by focusing on land productivity despite 
the fact that the main problem of Ethiopian agriculture is low labor productivity. Moreover, ADLI allegedly tends to emphasize the supply side with little concern for demand in the face of low purchasing power of the rural people on the one side.

So from the above idea, Policy-related challenges are not easy problem for development of extension service. Some DAs are reporting farmers' agricultural input demands to WOAD and the woreda cooperative agency without even consulting farmers, merely based on the previous year's data Because, they enforced by Woreda leaders and SMS. Most of the time extension agents are busy with political related activities; As a result, the agricultural extension work might lose its goals and objectives.

\subsubsection{Administrative and Institutional Challenges}

Institutional concern challenges of agricultural extension service are top down, limited private sector involvement in service delivery, lack of monitoring and evaluation of the extension system, lack system of agricultural inputs supply and distribution, involvement of experts on duties other than extension responsibility, weak market linkage and information system, weak linkage of research-extension farmer, absence of public private partnership in extension service delivery, Not enough attention given to indigenous knowledge of local people and absence of irrigated agriculture focused extension and research systems.

However, many front-line extension staff in Africa lack the competences (skills, knowledge, attitude and resulting behavior) they need to be effective in their work with farmers. In Ethiopia, the research-extension-farmers linkage platforms are very weak. The weakness of the linkages has been cited repeatedly as one of the major causes of underdevelopment in Ethiopian agriculture. The number and capacity of seed producers in the country never match with the demand of farmers. Lack of seeds is the most serious problem in meeting agricultural growth targets. For example: there is no adequate improved seed for wheat, barley, teff, or faba beans interview code no. 42, [2015]. Since hybrid seed production is a lucrative business for the producers, both government enterprises and private investors focus on hybrid maize seed production.

As mentioned by interview code no. 42, [2015] lack of seeds is the problem in meeting agricultural growth targets but we cannot justify this for all region of Ethiopia because, there is poor linkage between poor farmers and agricultural research and even extension agent. Technology that scale out from research is not based on selection of rural poor rather based on idea of model farmers those are small in number.

\subsubsection{ICT Related Challenges}

The challenges of access to ICT can be divided into two: (i) access to ICT infrastructure and (ii) access to ICT services. The access to ICT infrastructure in Ethiopia is still very low despite some

noticeable improvements registered in recent years. According to the country diagnostic report of the World Bank issued in March 2010, the coverage of ICT in Ethiopia is one of the lowest in Africa. For instance, the coverage of GSM signal is about 10 percent of the population compared to the 48 percent benchmark for low income countries. Similarly, at the time of assessment, the Internet bandwidth benchmark for low income countries is about 20 times higher than that of Ethiopia.

Mobile markets are one of the major factors behind the slow development of its ICT sector. Thus, despite the fact that ICT has immense potential in disseminating agricultural knowledge and information, the low level of ICT infrastructure in Ethiopia is believed to have hindered the sector from realizing its potential. This has inhibited the effectiveness of FTCs in creating and delivering agricultural knowledge for use by rural farmers to increase productivity and production and to enhance efficiency. In most places, FTCs are not connected to modern ICT infrastructure and services. As a result, research-extension-farmer linkages are weak and costly as such linkages have to be fostered through physical contact such as training, field demonstration, field day program and visits.

Table 2. Three main areas of application for ICTs in the agricultural sector.

\begin{tabular}{|c|c|c|}
\hline Enhancing productivity on the farm & ccessing markets and value chains & vice provision \\
\hline $\begin{array}{l}\text { ICTs have been utilized to: } \\
\text { 1. increase farm productivity, } \\
\text { 2. (support research, extension and advisory } \\
\text { services, } 3 \text {. for the provision and access to } \\
\text { financial services and } \\
\text { 4. for the management of farmer } \\
\text { organizations }\end{array}$ & $\begin{array}{l}\text { 1. accessing market and price information, } \\
\text { 2. facilitating the exchange and flow of information in } \\
\text { supply chains, } \\
\text { 3. risk management, information collection, storage, } \\
\text { processing and dissemination and } \\
\text { 4. in the implementation of traceability solutions }\end{array}$ & $\begin{array}{l}\text { ICTs are also utilized in: } \\
\text { 1. enhancing governance in rural agricultural } \\
\text { communities, } \\
\text { 2. improving land administration activities } \\
\text { and } \\
\text { 3. forest governance activity }\end{array}$ \\
\hline
\end{tabular}

From the above table, ICT is the driver of agricultural development and poverty reduction because there is no area of agricultural extension service achieved without ICT involvement. Therefore, there is no technology transfer without information and communication implies that there is no information and communication without ICT.

\subsubsection{Resources Mobilization}

Government budgetary support for agricultural extension in developing countries remains inadequate Adequate funding on decentralized extension organization will enhance the performance of extension organizations. A major problem in developing countries is allocation of inadequate resources, including funds and qualified extension staff to deliver extension services Developing country has no capacity to utilize resource that they have.

As we know that major problem of developing country, particularly rural poor was not dominated by lack of budget 
allocation but also unable to use resource what they have in their hands because of knowledge, skill, financial and other problems.

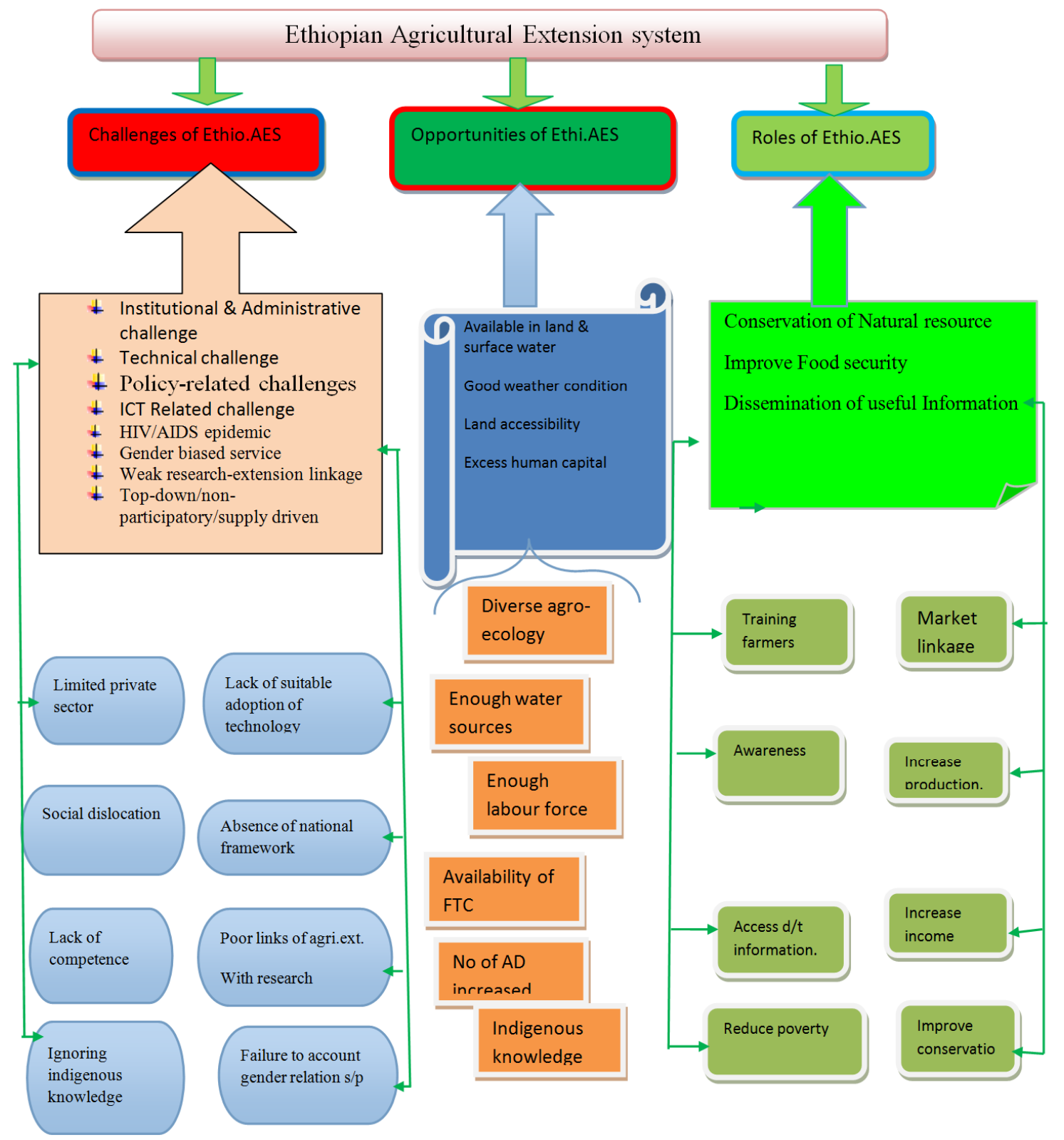

Figure 2. Theoretical framework of Agricultural Extension challenges, opportunity and roles.

\section{Conclusions}

The aim of Ethiopian agricultural extension system is to increase food security, farmers' livelihoods, and to promote sustainable land management. Agricultural extension systems of Ethiopia have different roles, opportunities and challenges that impact positively or negatively the countries' agricultural production and productivity. Agricultural extension systems of the country have also its own structures through which agricultural administration, information, communication and agricultural advisory service is given for farmers and these structures are used as bridge to connect agricultural technology with stakeholders, starting from input supplier up to end users or consumers.

\section{Abbreviation and Acronyms}

PADETES Participatory Demonstration and Training Extension Systems

PADETES Participatory Demonstration and Training Extension Systems

ATA Agricultural transformation Agency

MoA Ministry of Agriculture

AAS Agricultural Advisory Services

DA Development Agents

SMS Subject Matter Specialists

WOAD Woreda Office of Agricultural Development

NRM Natural Resource Management

NGOs Non-Government Organization 


$\begin{array}{ll}\text { UK } & \text { Unit Kingdom } \\ \text { GFRAS, } & \text { Global Forum for Rural Advisory Services } \\ \text { SDG-2 } & \text { Sustainable Development Goal Two } \\ \text { FTC } & \text { Farmers Training Center } \\ \text { ICT } & \text { Information Technology } \\ \text { BMGF } & \text { Bill and Melinda Gates Foundation } \\ \text { RARC } & \text { Regional Agricultural Research Center } \\ \text { EIAR } & \text { Ethiopian Institute of Agricultural Research } \\ \text { AED } & \text { Agricultural Extension Development } \\ \text { GTP } & \text { Growth and Transformation plan } \\ \text { SNNPRS } & \text { Southern Nations, Nationalities and People's } \\ \text { BoAD } & \text { Regional State } \\ \text { ToT } & \text { Bureau of Agricultural Development } \\ \text { ZOAD } & \text { Technology Transfer } \\ \text { AES } & \text { Zone Office of Agricultural Development } \\ \text { Agricultural Extension System } & \text { Woreda Office of Agricultural Development } \\ \text { TVET } & \text { Technical and Vocational Education Training }\end{array}$

\section{References}

[1] Abate, H., (2008). Agricultural extension in Ethiopia: Historical Evolution, Relevant Policies and Challenges. In: Taye Assefa (ed.) Digest of Ethiopia's national policies, strategies and programs. Addis Ababa, Ethiopia. ISBN 13; 978-99944-50-19-0.

[2] Davis, K., Swanson, B., Amudavi, D., Ayalew, D., Flohrs, A., Riese, J., Lamb, C., Zerfu, E., (2010). In-depth Assessment of the public Agricultural Extension System of Ethiopia and Recommendations for Improvement. IFPRI discussion paper 01041. Eastern and South Africa Regional Office. Addis Ababa, Ethiopia.

[3] Birner, R., Davis, K., Pender, J., Nkonya, E., Anandajayasekeram, P., Ekboir, J., Mbabu, A. Spielman, D., Horna, D., Benin, S., Cohen, M., (2006). From best practice to best fit: A framework for designing and analyzing pluralistic agricultural advisory services Worldwide. Discussion paper: DSGD-37, EPID-155, FCND-210 and ISNAR-5. IFPRI, Washington, DC, USA.

[4] Abate, H., (2007). Review of extension systems applied in Ethiopia with special emphasis to the Participatory Demonstration and Training Extension System (PADETS).

[5] Ministry of Finance and Economic Development (MoFED), (2010). Ethiopia: Country report on the implementation of the Brussels Program of Action (BPOA). Addis Ababa, Ethiopia.

[6] Berhanu, K., Poulton, C., (2014). The political economy of agricultural extension policy in Ethiopia: Economic growth and political control. Development policy review, 32 (2), 197213.

[7] Berhanu, K., (2012). The political economy of agricultural extension in Ethiopia: Economic growth and political control. Working paper 042. Future Agricultures.

[8] Agricultural Transformation Agency (ATA). (2014). Transforming Agriculture in Ethiopia. Annual Report.
[9] Stellmacher, T. (ed.), (2015). Socio-economic Change in Rural Ethiopia. Understanding Local Dynamics in Environmental Planning and Natural Resource Management. Peter Lang. Frankfurt.

[10] OXFAM. (2016). El Niño in Ethiopia: Program observations on the impact of the Ethiopian drought and recommendationforaction. OXFAMEINiño Briefings. I https://www.oxfam.org/sites/www.oxfam.org/files/file_attach ments/bn-el-nino-ethiopia-240216-en.pdf

[11] Stellmacher, T., (2007). The historical development of local forest governance in Ethiopia. From imperial times to the military regime of the Derg. In: Afrika Spectrum 42 (3). GIGA Institute of African Affairs, Hamburg.

[12] Ministry of Agriculture (MoA), (2012). Agricultural cooperative sector development strategy (2012-2016). Addis Ababa, Ethiopia.

[13] Gebremedhin, B. Hoekstra, D., Tegegne, A., (2006). Commercialization of Ethiopian agriculture: Extension service from input supplier to knowledge broker and facilitator. IPMS (Improving Productivity and Market Success) of Ethiopian Farmers Project Working Paper 1. ILRI, Nairobi, Kenya.

[14] Ministry of Agriculture (MoA), (2015). DA tracking study report for Oromia region. Development Studies Associate. Addis Ababa, Ethiopia.

[15] Van Assche, K., 2016. Afterwards: Expertise and rural development after the soviets. In: Hornidge, A-K., Shtaltovna, A., and Schetter, C. (Eds). 2016. Agricultural knowledge and knowledge systems in Post-Soviet Societies. Interdisciplinary Studies on Central and Eastern Europe Vol. 15. Peter Lang, Frankfurt.

[16] Christoplos, I., (2010). Mobilizing the potential of rural and agricultural extension. Food and Agriculture Organization (FAO) of the United Nations and Global Forum for Rural Advisory Services. FAO, Rome.

[17] Rivera, W. M., Sulaiman, V. R. (2009). Extension: object of reform, engine for innovation. Outlook on Agriculture.

[18] Ekpo, A., (2008). 'Decentralization and service delivery: a framework', paper prepared for the African Economic Research Consortium, Nairobi.

[19] Swanson, B. E., Rajalahti, R., (2010.) Strengthening agricultural extension and advisory systems: Procedure for assessing, transforming, \& evaluating extension systems. World Bank, Washington, DC. 20433.

[20] Habib, M., Mohammed, A., (2010). The Ethiopian federal system: the formative stage. Friedrich-Ebert-Stiftung, Addis Ababa, Ethiopia.

[21] Ministry of Agriculture (MoA), (2010). Development Agents career structure guideline (Amharic version). Addis Ababa, Ethiopia.

[22] Maguire, C. J., (2012). Education and training for technical development. In: Agricultural Innovation Systems. An investment source book. The World Bank, Washington D.C.

[23] Zwane, E. M., (2012). Does Extension Have A Role To Play In Rural Development? South African Journal Agricultural Extension. Vol. 40: 24 16 - ISSN 0301-603X. 